\title{
Failure and Protective Measures on Punch \& Die for Cold Extrusion
}

\author{
Bohai He \\ Department of Numerical Control Engineering \\ Zhejiang Industry Polytechnic College \\ Shaoxing, China, 312000
}

\begin{abstract}
Because of some irrationality of the design, material selection and heat treatment, earlier failure phenomenon often occurs in cold extrusion die. These failure phenomena of cold extrusion dies have been studied and measures to solve the failures are proposed.
\end{abstract}

Keywords-Cold Extrusion Die, Failure Form, Protective Measures

\section{INTRODUCTION}

With the development of modern manufacturing technology and the change of its structure, cold extrusion process, being saving raw materials and having higher production efficiency, is widelier and widelier used by many enterprises. However, during the course of using cold extrusion die, the life of mold forming parts (i.e. punch and die), to a large extent, determines the entire life of the mold for rigorous working conditions of forming parts. At present, in many businesses using cold extrusion process, the service life of extrusion die is very low, the main reason is that the staff of the mold design, manufacture and use lack adequate understanding for die working conditions, performance, cause of damage, mold material properties and processing technology. In 1998, Zhejiang Shaoxing bike flywheel limited liability company used a cold extrusion process to produce the flying bicycle flywheel shell. The company is an domestic production enterprise early using cold extrusion process. In the last 20 years of design and manufacture of clod extrusion die, some experience was accumulated.

\section{FAILURE PHENOMENA}

The main failure forms of cold extrusion dies are wear, plastic deformation, fatigue damage and fracture.

Wear: during the course of cold extrusion, due to the blank not only sliding and also flowing along the surface of the mold, the mold working surface is bound to suffer wear. In fact, the quick wear of extrusion die is caused by such reasons as their low surface hardness, poor brication and large deformation resistance.

Plastic:Deformation As is shown in Figure 1, an extrusion punch whose first material is $\mathrm{Cr} 12 \mathrm{MoV}$ is upsetted. Due to various reasons, in the cold extrusion, punch will often have a 0.2 to $0.5 \%$ plastic deformation after several extrusions or dozens of times. the main form of plastic deformation is upsetting, deformation and bending etc.

Fatigue Failure the essential reason of fatigue failure is stress concentration and cyclic loading. The process of fatigue failure of the mold generally can be divided into two stages as fatigue crack initiation and fatigue crack growth. Especially the early failure of extrusion die is caused by fatigue failure.

Fracture: Fracture is the most common form of damage and also the most damaging form directly affecting the die life. The fracture of a punch often begins with a tiny cut or scratch marks, and then gradually expands to form a circular crack and finally the punch sudden breaks.
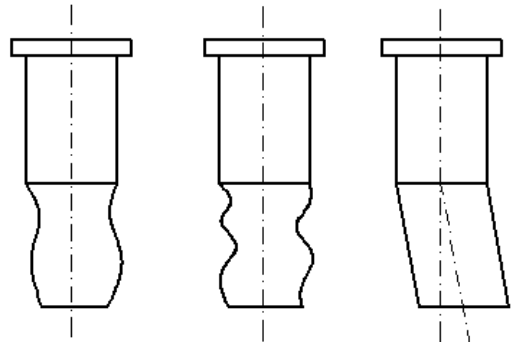

(a) Upsetting (b) plastic deformation (c) bending

Figure 1. Main Form of Plastic Deformation

Punch Fracture: according to destructive character and form, punch fracture is divided into 3 categories - horizontal cracks, vertical cracks and radial cracks respectively. Whle horizontal crack can be divided into breaking for bending and tensile breaking (see Figure 2). There are other forms of network cracks and swap blocks and so on.

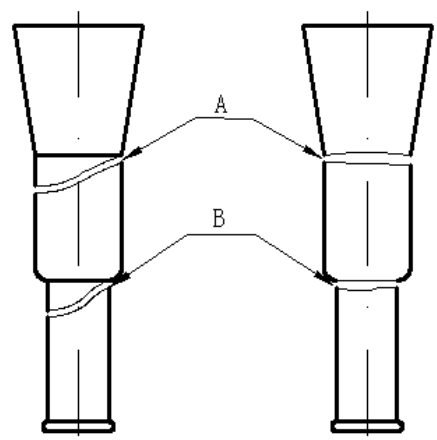

(a) Breaking for bending (b) tensile breaking

Figure 2. Main Form of Plastic Deformation

(1) Breaking for Bending (Figure 2(a))

Breaking for Bending is a common form of punch fracture, fracture location is mostly in the transition ladder and the fracture is tilted. On the fracture surface, fracture stripes, fracture area and direction can be seen.

(2) Tensile breaking (Figure 2(b)) 
In actual use, tensile breaking of a punch often occurs in the case of deterioration of lubrication conditions. every piece unloading time, will have a punch attached to Niagara on the role of stress. Pull off the part of the transition are changes in the cross section at the fracture formation.

(3) Longitudinal Crack (Figure 3(a))

This crack Often occurs in the circle area and belongs to fatigue crack. It is led to by hot and cold alternating stress or poor lubrication or unenough surface hardness of a punch, Center cracking (see Figure $3 b, c$ ) is mostly caused by material defects, such as uneven distribution of the deflection, too large carbides, etc.

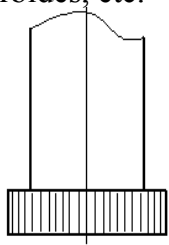

(a)

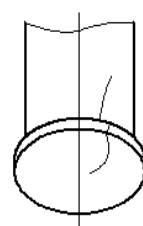

(b)

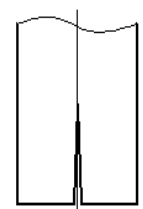

(c) (a) Longitudinal Crack Pattern (b) Longitudinal Breaking (c)Centre Splitting

Figure 3. Longitudinal Crack

(4) Net crack (Figure 4)

The network crack is caused by thermal effects when compression, mold excessive grinding in the process, the feed too quickly and the surface cracks by overheating will develop into net cracks.

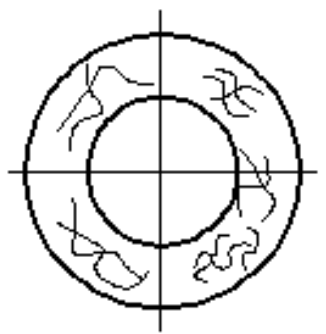

Figure 4. Net crack on Side surface of the work

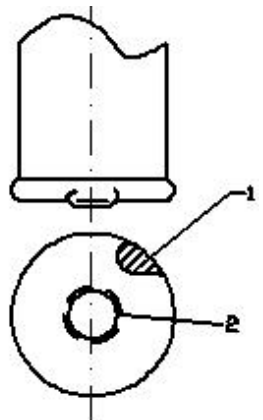

Figure 5. cracking and Block off on the workpiece surface

(5) block off (Figure 5)

Block off of a punch is an isolated phenomenon of the depart of the local and the whole body forming, and it is the phenomenon of thermal fatigue. It is caused Mainly by the local material defects.

\section{Protective Measures}

The above phenomena are seemingly isolated, in fact, there is a certain internal relations among them. In order to increase the life of cold extrusion die, the central toughness and the surface abrasion resistance of die need be improved, but more important is the rational design of die structure, on this basis, the correct selection of mold materials, the implementation of rational treatment process and the correct formulation of manufacturing process.

(1)Determining the structure of the mold

Reasonable die structure can cause work force more uniform, stress concentration smaller and uneasy partial load.

1) fillet radius In general, the extrusion forming force will increase if the convex radius is too small, this could easily lead to forging fold (defect). It also will force the local deterioration of the mold, at the fillet radiu has a greater stress concentration, crack initiation, resulting in fracture, and finally this results in reduced die life. Larger radius could cause extrusion force even.

The concave fillet radius have important influence to the service life of mould. If spare parts of the concave fillet radius is too small, it will make the mould stress concentration, anti slanting load, impact resistant capacity reduction. Figure 7 is the concave mould of reverse squeeze cup shape, making the service life of mould doubled because R2.5 changed to R5. As figure 6 shows:

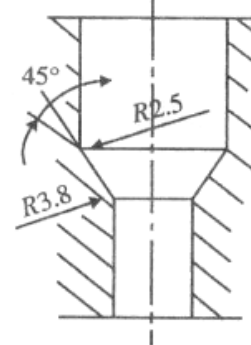

(a)

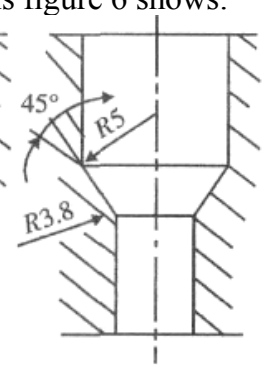

(b) (a) producing 1.5 million pieces (b) producing 3 million pieces

Figure 6. fillet radius of influence on die life

2) mould geometric shapes

Figure 8 begins to record some data of cold extrusion, it describes the extrusion of dies on the angle and extrusion pressure. For the same angle of concave die, extrusion pressure is smaller, then die life will be higher. Figure 9 is the reverse squeeze cup shape of two different forms of terrace die. Type a structure makes extrusion pressure reduce $25 \%$ than type b structure, die life improved greatly.
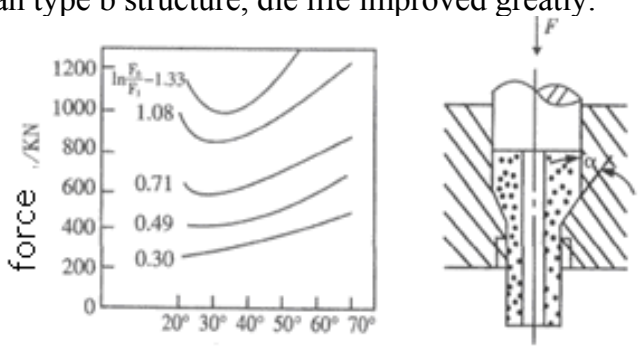

extrusion angle 
Figure 7. the geometry of cold extrusion concave

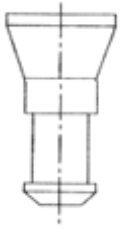

(a)

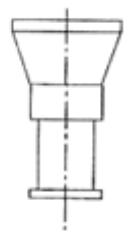

(b) a - convex end type $b$ - flat end type

Figure 8. comparison of two terrace die structure die on the influence of extrusion pressure

3) Integral mould and framed spell mould

The integral mould has inevitably concave round radius in manufacturing process, it is easy to cause stress concentration, then causecraze.Integral mould (a) in figure 9, figure 10 exists the crack, framed spell mould (b) avoids crack. In addition, adopting prestressed reinforcement ring, can make the mould produce pre tangential compressive, reduce the forming process of tensile stress peak, effectively improve die life.
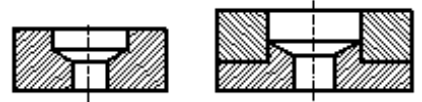

a)integral structure b) tetrad structure

Figure 9. dies of integral and framed spell

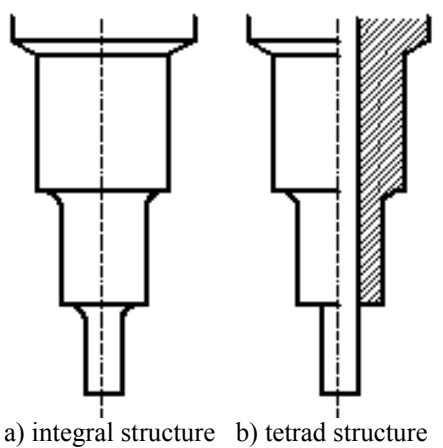

Figure 10. terrace die of integral and framed spell

(2) mould material selection

Cold extrusion dies receive mechanical force as stretching ,compression, impact, fatigue and friction $\mathrm{n}$ working, and the deformation resistance is very big, extrusion dieoften received the stress about $2000 \mathrm{MPa}$, and the mould billet plastic deformation will produce mould temperature overheats, make up to $200{ }^{\circ} \mathrm{C}-300{ }^{\circ} \mathrm{C}$. The invalidation forms mostly are wear, brittle fracture, plastic deformation and bite, etc. Therefore, cold extrusion mold steels should have:

1) good wear resistance;

2) the enough strength and toughness;

3) good red rigid;

4) resistance performance of binding ability.
Then, the chemical composition of materials will directly influence the microstructure and properties of materials, affect the service life of the die. We found in using :

1) $\mathrm{Cr} 12 \mathrm{MoV}$ steel has high wear resistance, but its carbide segregation can cause serious deformation of the directional and tenacity reduced. compared the $\mathrm{Cr} 12 \mathrm{MoV}$ steel, D2 steel die life have different degrees of improvement.

2) W6Mo5Cr4V2 and $\mathrm{W} 18 \mathrm{Cr} 4 \mathrm{~V}$ have high wear resistance and strength, often used to make bear larger impact extrusion of cold extrusion die, but its toughness cannot satisfy needs on complex and large impact load mould.

3)In the basis of CrWMn steel, GD steel properly reduce carbon content to reduce the carbide segregation, but also increase nickel, silicon, manganese to increase strength and toughness of matrix , then it can partially replaced $\mathrm{Cr} 12 \mathrm{MoV}$ steel manufacturing mold.

4)LD steel has both the intensity of high toughness and wear resistance.It has excellent performance and little deformation. Its carbon and chrome content is much lower than $\mathrm{Cr} 12 \mathrm{MoV}$ steel, reduced chrome content to improve their carbon segregation, increase the content of Mo and V, and to increase the second sclerosis ability and high wear resistance, so LD steel has high tenacity.

(3) Heat treatment process

The purpose of the mould heat treatment is to obtain the ideal micmstructure and various mechanical properties. After hardening,cold extrusion mold steels microstructure should be: in martensite, distributing small, uniform, circle, high dispersion of granular carbide. Therefore,in our actual manufacturing process, through optimizing heat treatment process to get small, dispersion distribution of granular carbide to improve the mould wearability and strong toughness.

The following table is the records of the mechanical properties of high-toughness wear-resistant steel, which is passed through different quench and tempering temperatures.

As can be seen from the table, the quenching temperature range of high-toughness wear-resistant steel is wide. It is generally in the range of $1100-1180{ }^{\circ} \mathrm{C}$. After quenching, the large undissolved eutectic carbide in the matrix decreased, while preserving many small, uniforms, round granular alloy carbides. In the tempering temperature range of $510-620{ }^{\circ} \mathrm{C}$, the matrix will separate out a large number of dispersed alloy carbide precipitation, causing secondary hardening phenomenon after tempering.

It is appropriate for choosing the quenching temperature of the test mold in 1100-1150 ${ }^{\circ} \mathrm{C}$. Quenching is composed of quenching martensite, residual austenite and undissolved carbides. After tempering at $550{ }^{\circ} \mathrm{C}$ the mechanical properties is the best.

(4) The lubrication of cold extrusion

In the cold extrusion, mold needs to bear a huge load.

In the process of metal flow, it is also affected by the great force of friction and temperature changes.

Thus deformation heat and friction heat increase the temperature of the mold to $200-300{ }^{\circ} \mathrm{C}$. 
Therefore, it can grow the mold life in a certain extent by taking good lubrication to reduce friction and heat.

1) Lubrication of the workpiece

We found: the workpiece surface quality after lubricating should meet the following requirements:

- The lubricating film should be uniform, crystal structure should be fine, and the combination should be firm and feel slippery. Phosphate is light gray to medium gray, oxide film is gray or dark brown.

- The lubricating surface does not allow bare metal.

- The lubricant in the blank or semi-finished production surface is not allowed depositing into blocks and nodulation phenomena.

- The parts should be immediately dried completely after saponification. It should be used immediately after saponification, because the moisture absorption of saponification layer is strong

- In the lubrication of the workpiece, the lubricating layer of the middle process with a larger deformation is thick. It is thicker in anti-extrusion than extrusion. The workpiece lubrication layer should not be too thick in the final shape.

2) Mold lubrication

It is Generally determined based on workpiece material, shape and size.

Graphite lubricant (such as colloidal graphite), molybdenum disulfide lubricants, paint mixing zinc oxide and sodium silicate are generally used (Such as graphite for the place of high temperature and slow deformation).

\section{CONCLUTIONS}

The following measures can be used to improve the the life of cold extrusion convex and concave mold.

(1) Design and manufacture correctly the mold suitable for cold extrusion.

Mold structure design should avoid stress concentration as much as possible.

Radius has a great impact on the mold life. Radius should be appropriate. At the same time, the manufacturing precision of the mold should be improved. Especially, improving the precision of extrusion part can greatly extend the life of the mold.

(2) Prevent grinding cracks. In the grinding of the workpiece after quenching and tempering, cracks are often produced by improper grinding. Sometimes, the cracks don't disappear even by reducing the amount of grinding. At this time we can do a low-temperature tempering and reduce the amount of grinding to eliminate the grinding cracks.

(3) Correctly choose cold extrusion mold material and thermal processing technology.

Regularly do stress relief annealing to eliminate internal stress. it is very beneficial to improve the mold life by 160 180 annealing to remove stress when The mold has been used for some time.

(4) Correctly choose the deformation degree of cold extrusion to avoid excessive deformation, which can cause the increasing of the extrusion force and leading to mold damage.

Thus, we should make the metal deformation strength of the material as low as possible generally and take annealing or hardening softening rough treatment for the extrusion billet

Minimize deformation of extrusion to decrease extrusion pressure. Surface treatment and lubrication is needed to produce a lubricating layer between deformation of billet and mold. The lubricating layer can avoid the direct contact between deformation of billet and mold. It can reduce the friction, the deformation force and mold wear.

(6) Choose the appropriate equipment with accuracy orientation and good rigidity.

(7) Enhance lubrication effect..

\section{REFERENCES}

[1] Research on cold extrusion of primer body made of Brass[J]. Ordnance materian science and engineering, 2005,(06)

[2] Zhou Meijuan. Cold extrusion mold structure design[J]. Metal Forming Technology, 1996,(06) .

[3] Jiang Xiyan, Guo Ying. Application of steel cold extrusion connections technology in Construction[J]. Journal of Hebei Institute of Architectural Engineering, 2001,(03)

[4] Liu Chunling, Zhang Lianyao. Discussion of cold extrusion mold life [J]. Journal of Hebei Institute of Architectural Science \& Technology, 2004,(04).

[5] Han Xiuying. The material selection of cold extrusion mold and Practice Effect $[\mathrm{J}]$. Design and manufacture of diesel engines, 1995,(01)

[6] Hong Shenzhang. Technological Design of Parts for the Cold Extrusion [J]. Die and mould technology, 2004,(03)

[7] Yu Ling. the study on extrusion forming technology of two-cup part [D]. North university of China, 2006

[8] Wang Jia. Influence of backward extrusion punch shape to the extrusion process [J]. Die and mould technology, 2009,(01)

\begin{tabular}{|c|c|c|c|c|c|}
\hline $\begin{array}{c}\text { Quench } \\
\text { temperature }{ }^{\circ} \mathrm{C}\end{array}$ & $\begin{array}{c}\text { Tempering } \\
\text { temperature } \\
\text { and frequency }\end{array}$ & $\begin{array}{c}\text { Tensile } \\
\text { strength } \\
\text { MPa }\end{array}$ & $\begin{array}{c}\text { Compressive } \\
\text { strength } \\
\mathrm{MPa}\end{array}$ & $\begin{array}{c}\text { Bending } \\
\text { strength } \\
\mathrm{MPa}\end{array}$ & $\begin{array}{c}\text { Toughness } \\
\mathrm{J} / \mathrm{cm}^{2}\end{array}$ \\
\hline 1100 & $\begin{array}{l}550^{\circ} \mathrm{C} / 1 \mathrm{~h} \times 3 \\
570^{\circ} \mathrm{C} / 1 \mathrm{hx} 3 \\
590^{\circ} \mathrm{C} / 1 \mathrm{hx} 3\end{array}$ & $\begin{array}{l}2580 \\
2500\end{array}$ & $\begin{array}{l}2550 \\
2340 \\
2080\end{array}$ & $\begin{array}{l}5430 \\
4990 \\
4380\end{array}$ & $\begin{array}{c}116 \\
104 \\
48\end{array}$ \\
\hline 1150 & $\begin{array}{l}550^{\circ} \mathrm{C} / 1 \mathrm{~h} \times 3 \\
570^{\circ} \mathrm{C} / 1 \mathrm{~h} \times 3 \\
590^{\circ} \mathrm{C} / 1 \mathrm{~h} \times 3\end{array}$ & $\begin{array}{l}2680 \\
2680 \\
2340\end{array}$ & $\begin{array}{l}2866 \\
2660 \\
2230\end{array}$ & $\begin{array}{l}5590 \\
5190 \\
4790\end{array}$ & $\begin{array}{c}98 \\
104 \\
82\end{array}$ \\
\hline 1180 & $\begin{array}{l}550^{\circ} \mathrm{C} / 1 \mathrm{hx} 3 \\
570^{\circ} \mathrm{C} / \mathrm{h} \times 3 \\
590^{\circ} \mathrm{C} / 1 \mathrm{hx} 3\end{array}$ & $\begin{array}{l}2770 \\
2610 \\
2470\end{array}$ & $\begin{array}{l}2810 \\
2700 \\
2490\end{array}$ & $\begin{array}{l}5080 \\
4730 \\
4880\end{array}$ & $\begin{array}{l}73 \\
45 \\
42\end{array}$ \\
\hline
\end{tabular}

